\title{
Hepatitis B core-related antigen: a strong indicator for cessation of nucleos $(t)$ ide analog therapy in patients with chronic hepatitis $B$
}

\author{
Akihiro Matsumoto \\ Received: 25 July 2016/Accepted: 4 August 2016/Published online: 24 September 2016 \\ (C) Japanese Society of Gastroenterology 2016
}

With successful nucleos(t)ide analog therapy, serum hepatitis B virus (HBV) DNA titer decreases to below detection limit, alanine aminotransferase (ALT) normalizes, and fibrosis of the liver may become improved [1-4]. The incidence of hepatocellular carcinoma can be decreased as well [5-7].

However, withdrawal hepatitis frequently occurs after treatment cessation, even in patients with undetectable HBV DNA levels. As this complication is sometimes lethal [8-10], it is crucial to determine the optimal conditions for stopping nucleos(t)ide analog therapy, especially for young patients wishing to have children, the avoidance of hyper-resistant viral strains, and regulating medical expenses.

Knowledge of intrahepatic HBV replication status is the key to defining the safe conditions for nucleos(t)ide analog therapy cessation. cccDNA level is a suitable indicator for this aim, although frequent liver biopsies are needed. Serum HBV DNA was believed to be a good estimator of cccDNA. However, the correlation of HBV DNA and intrahepatic cccDNA levels is lost under the nucleos $(\mathrm{t})$ ide analog treatment and cannot therefore be adopted [11]. Alternative, non-invasive markers are desired.

The possibility of discontinuation of nucleos(t)ide ana$\log$ is also affected by the clinical goal, such as no withdrawal hepatitis, no viral relapse, or long-term clinical response. The majority of patients experience viral recurrence during withdrawal, but some will not develop

Akihiro Matsumoto

amatsumo@shinshu-u.ac.jp

1 Department of Medicine, Shinshu University School of Medicine, Asahi 3-1-1, Matsumoto 390-8621, Japan hepatitis or will achieve clinical remission after a hepatitis flare.

In this issue, Jung $\mathrm{KS}$ et al. [12] report on virological remission (i.e., HBV DNA $\leq 2000 \mathrm{IU} / \mathrm{ml}$ ) over 1 year following cessation of nucleos $(\mathrm{t})$ ide therapy in patients HBeAg-positive or HBeAg-negative at the start of treatment. The virological relapse rate of each group was 57.8 and $54.4 \%$, respectively. Significantly and independently related factors for virological relapse were age $>40$ years at the start of nucleos(t)ide therapy and basal HBV DNA level $>20,000,000 \mathrm{IU} / \mathrm{ml}$ in the $\mathrm{HBeAg}$-positive group, and age $>40$ years at the start of nucleos(t)ide analog therapy and $\mathrm{HB}$ core-related antigen (HBcrAg) level $>3.7 \mathrm{log} \mathrm{U} / \mathrm{ml}$ in the HBeAg-negative group.

$\mathrm{HBcrAg}$ is an established viral activity marker [13]. HBcrAg levels correlated closely with those of intrahepatic cccDNA, even when HBV DNA became undetectable, during nucleos(t)ide analog therapy [11]. Thus, HBcrAg may represent a non-invasive marker of cccDNA with or without nucleos(t)ide analog therapy. We have also reported that a combination of $\mathrm{HBsAg}$ and $\mathrm{HBcrAg}$ levels at the end of nucleos(t)ide analog therapy was useful to predict long-term clinical remission [14, 15].

According to APASL guidelines, the appropriate duration of nucleoside analog administration is unknown, although HBV DNA and HBsAg are suggested as estimators of treatment efficacy [16]. There are no precise criteria for the cessation of nucleos(t)ide analog therapy in the EASL guidelines as well [17]. In the AASLD guidelines, HBsAg loss is regarded as the best predictor of sustained remission off-treatment, but is also reported to be infrequent with current therapies [18].

In this issue, the authors present clear criteria for successful discontinuation of nucleos(t)ide analog therapy using HBcrAg, which is expected to contribute to the 
enhancement of chronic hepatitis B patient management. Their study also underscores the importance of measuring multiple HBV antigens in addition to HBV DNA to better estimate the behavior of $\mathrm{HBV}$ in the liver.

\section{Compliance with ethical standards}

Conflict of interest The author declares there is no conflict of interest.

\section{References}

1. Chang TT, Gish RG, de Man R, et al. A comparison of entecavir and lamivudine for HBeAg-positive chronic hepatitis B. N Engl J Med. 2006;354:1001-10.

2. Lai CL, Shouval D, Lok AS, et al. Entecavir versus lamivudine for patients with $\mathrm{HBeAg}$-negative chronic hepatitis B. N Engl J Med. 2006;354:1011-20.

3. Lai CL, Chien RN, Leung NW, et al. A one-year trial of lamivudine for chronic hepatitis B. Asia Hepatitis Lamivudine Study Group. N Engl J Med. 1998;339:61-8.

4. Suzuki Y, Kumada H, Ikeda K, et al. Histological changes in liver biopsies after one year of lamivudine treatment in patients with chronic hepatitis B infection. J Hepatol. 1999;30:743-8.

5. Liaw YF, Sung JJ, Chow WC, et al. Lamivudine for patients with chronic hepatitis B and advanced liver disease. N Engl J Med. 2004;351:1521-31.

6. Matsumoto A, Tanaka E, Rokuhara A, et al. Efficacy of lamivudine for preventing hepatocellular carcinoma in chronic hepatitis B: a multicenter retrospective study of 2795 patients. Hepatol Res. 2005;32:173-84.

7. Hosaka T, Suzuki F, Kobayashi M, et al. Long-term entecavir treatment reduces hepatocellular carcinoma incidence in patients with hepatitis B virus infection. Hepatology. 2013;58:98-107.
8. Honkoop P, de Man RA, Niesters HG, et al. Acute exacerbation of chronic hepatitis $\mathrm{B}$ virus infection after withdrawal of lamivudine therapy. Hepatology. 2000;32:635-9.

9. Honkoop P, de Man RA, Heijtink RA, Schalm SW. Hepatitis B reactivation after lamivudine. Lancet. 1995;346:1156-7.

10. Liu F, Wang L, Li XY, et al. Poor durability of lamivudine effectiveness despite stringent cessation criteria: a prospective clinical study in hepatitis B e antigen-negative chronic hepatitis B patients. J Gastroenterol Hepatol. 2011;26:456-60.

11. Suzuki F, Miyakoshi H, Kobayashi M, Kumada H. Correlation between serum hepatitis B virus core-related antigen and intrahepatic covalently closed circular DNA in chronic hepatitis B patients. J Med Virol. 2009;81:27-33.

12. Jung KS, Park JY, Chon YE, et al. Clinical outcomes and predictors for relapse after cessation of oral antiviral treatment in chronic hepatitis B patients. J Gastroenterol. 2016;51:830-9.

13. Kimura T, Rokuhara A, Sakamoto Y, et al. Sensitive enzyme immunoassay for hepatitis B virus core-related antigens and their correlation to virus load. J Clin Microbiol. 2002;40:439-45.

14. Matsumoto A, Tanaka E, Suzuki Y, et al. Combination of hepatitis B viral antigens and DNA for prediction of relapse after discontinuation of nucleos(t)ide analogs in patients with chronic hepatitis B. Hepatol Res. 2012;42:139-49.

15. Tanaka E, Matsumoto A. Guidelines for avoiding risks resulting from discontinuation of nucleoside/nucleotide analogs in patients with chronic hepatitis B. Hepatol Res. 2014;44:1-8.

16. Sarin SK, Kumar M, Lau GK, et al. Asian-Pacific clinical practice guidelines on the management of hepatitis B: a 2015 update. Hepatol Int. 2016;10:1-98.

17. European Association For The Study Of The Liver. EASL clinical practice guidelines: management of chronic hepatitis B virus infection. J Hepatol. 2012;57:167-85.

18. Terrault NA, Bzowej NH, Chang KM, et al. AASLD guidelines for treatment of chronic hepatitis B. Hepatology. 2016;63: 261-83. 